\title{
O ESPAÇO URBANO: A ABORDAGEM DA ESCOLA DE CHICAGO E DA ESCOLA MARXISTA
}

Glaucio José Marafon

Departamento de Geociências - Centro de Ciências Naturais e Exatas UFSM - Santa Maria, RS.

RESUMO:

O ESPAÇO URBANO: A ABORDAGEM DA ESCOLA DE CHICAGO E DA ESCOLA MARXISTA

O espaço urbano e sua abordagem tem suscitado interpretações que se agrupam em matrizes teórico-metodológicas, em paradigmas, que passam a orientar as investigações sobre o espaço urbano. Esse ensaio tece considerações gerais sobre as propostas que orientam a abordagem do espçao urbano pelas Escolas de Chicago e Marxista.

\section{ABSTRACT:}

THE URBAN SPACE: THE APPROACH OF CHICAGO CURRENT AND MARXIST CURRENT

The urban space and its approach have arisen interpretations that gather themselves into theoretical-methodologial sources, into paradigms which guide the investigations about urban space. This essay comments on general considerations concerning proposals that guide the urban space approach of Chicago and Marxist Currents.

PALAVRAS-CHAVE: Espaço Urbano, Escola de Chicago, Escola Marxista. 


\section{INTRODUÇÃO}

A temática urbana tem sido analisada pelos mais diversos cientistas sociais: sociólogos, filósofos, economistas, antropólogos, historiadores, urbanistas e geógrafos, além de interessar a planejadores e políticos, e muitos estudos sobre a cidade têm sido realizados.

O interesse crescente sobre os processos sócio-espaciais, verificados nas cidades, decorre do fato da passagem de uma sociedade industrial para uma sociedade urbana [Lefebvre (1976)]. A cidade, além de concentrar parcela significativa da população, se converte cada vez mais em centro de poder e fonte de benefícios. A realidade urbana tornou-se mais complexa. Essa complexidade leva a uma reflexão sobre os paradigmas que orientam as pesquisas sobre o urbano.

A ciência geográfica também tem contribuído para essa reflexão. Tradicionalmente, a geografia urbana realiza estudos sobre a cidade e a considera sob um duplo aspecto: um que, leva em consideração uma ou várias cidades localizadas em uma região ou país, e, outro, que considera a cidade como espaço urbano, abordagens que não são excludentes entre si nem exclusivas da geografia.

O espaço urbano "apresenta várias características que interessam ao geógrafo é fragmentado e articulado, reflexo e condição social e campo simbólico e de lutas" [Corrêa (1991:01)] e sua abordagem tem suscitado interpretações diversas e que se agrupam em matrizes teórico-metodológicas, escolas, paradigmas, que passam a orientar as investigações sobre o espaço urbano.

Entre as escolas que mais contribuem com os estudos urbanos estão a Escola de Chicago e a Escola Marxista.

No presente ensaio, procuramos traçar as características gerais dessas duas escolas: a Escola de Chicago e a Escola Marxista.

Iniciamos este trabalho, caracterizando a Escola de Chicago, explanando os conceitos e postulados utilizados na análise do espaço urbano, além de levantar algumas das limitações do paradigma desta Escola.

$\mathrm{Na}$ segunda parte do trabalho, traçaremos as principais características da Escola Marxista em relação à abordagem do espaço urbano. 
Apresentaremos as diretrizes gerais e os agentes que atuam na produção do espaço urbano.

Destacaremos, nesta abordagem, a utilização da teoria do valor de uso de troca, o processo de segregação residencial e a presença dos agentes que atuam na produção do espaço urbano: os proprietários dos meios de produçãó, os proprietários fundiários, os promotores imobiliários, o Estado e os grupos sociais excluídos.

A escolha sobre estas duas escolas ocorreu pelo fato de serem antagônicas e orientarem um grande número de investigações sobre o espaço urbano.

\section{A ESCOLA DE CHICAGO E A ABORDAGEM DO ESPAÇO URBANO}

Os estudos realizados, sobre a cidade, pelos cientistas sociais, sobretudo os sociólogos, da Universidade de Chicago (EUA) resultaram em um conjunto de proposições e conceitos que orientaram a análise do urbano por um longo período de tempo.

Entre esses cientistas, destacamos as contribuições de R. Park, E. Burgess e R. Mckenzie, que traçaram, no início deste século, as linhas básicas da análise do urbano. Estes autores são considerados os fundadores e orientadores da denominada Escola de Chicago ou Ecologia Humana.

A denominação de Ecologia Humana para esta escola decorreu, fundamentalmente, por "tentar veicular as formas de comunidades nos processos de organização social" [Gottdiener (1993:35)] e a tentativa de transposição dos princípios da Ecologia aos estudos da sociedade.

Os pesquisadores da Escola de Chicago assimilaram os conceitos da Ecologia e passaram a aplicá-los aos estudos das comunidades urbanas.

A Ecölogia, como ciência, surgiu no final do século passado, para estudar as relações dos organismos vivos com o ambiente, e Haechel a definiu como sendo:

"...o estudo da economia, da organização doméstica dos organismos animais. Inclui as relações dos animais com o ambiente orgânico e inorgânico, especialmente todas as relações benéficas $e$ inimigas que Darwin mencionava como 
representando as condições de luta pela existência" Apud Viertler (1988:05).

A ecologia surgiu embasada no naturalismo desenvolvido no século XIX, inspirada nas idéias evolucionistas de Darwin e na analogia biológica provinda do positivismo.

A ciência ecológica inspirou os pesquisadores da Escola de Chicago na formulação das proposições e conceitos para o estudo da cidade. A Escola de Chicago pode ser caracterizada fundamentalmente por estudar:

- As relações do homem com o meio, descrevendo os aspectos sociais de adaptação;

- A forma e o desenvovimento em comunidade da população humana, descrevendo o processo de organização das relações implicādas na adaptação ao meio.

Destacamos a importância que a noção de adaptação e equilíbrio assumem na investigação para os pesquisadores da Escola de Chicago.

Temos, assim, uma matriz teórico-metodológica desenvolvida pela Escola de Chicago denominada Ecologia Humana e que consistiria:

"...fundamentalmente, em uma tentativa de investigação dos processos pelos quais o equilíbrio biótico e o equilíbrio social se' mantêm uma vez alcançados, e dos processos pelos quais, quando o equilíbrio biótico e o equilíbrio social são perturbados, se faz a transição de uma ordem relativamente estável para outra". [Park (1948:36)].

A analogia biológica representou uma aproximação entre as ciências sociais e naturais, e aconteceu em um momento histórico especifico, onde ocorria a expansão da sociedade industrial e a consolidação do colonialismo associado à idéia de progresso, do liberalismo econômico: da "liberdade de fazer."

Para explicar essa realidade, os pesquisadores da Escola de Chicago buscaram, principalmente na Ecologia Vegetal e Animal, as concepções teóricas que passaram a nortear as investigações.

Concentraram seus esforços na tarefa de entender os processos de mudanças que ocorriam na superficie da terra, com o intuito de desvendar os principios de sua operação e a natureza das forças que os produziam.

Os resultados dessas pesquisas ficaram conhecidos como estudos de Ecologia Humana. Porém, a Ecologia Humana resulta, antes de tudo, como 
Ecologia Urbana, e essa realidade é decorrente da tentativa de explicar os fenômenos das grandes cidades, principalmente das áreas metropolitanas que apresentavam um grande crescimento no início do século.

Os pesquisadores da Escola de Chicago realizaram uma análise empírica do crescimento acelerado que ocorria nas grandes cidades americanas, decorrente do grande contingente imigratório que ocorria no início do século. Essas cidades serviram como "laboratórios" para os estudos dos ecólogos humanos.

Nesse contexto, foram identificados e propostos conceitos e processos para o estudo da cidade, que perduram até os dias atuais. Entre os conceitos, destacamos os de comunidade urbana, mobilidade, fluidez e distância, e os processos de concentração, centralização, segregação, invasão e sucessão.

\section{1- CONCEITOS E PROPOSIÇÕES UTILIZADOS PELA ESCOLA DE CHICAGO NA ABORDAGEM DO ESPAÇO URBANO}

Comunidade urbana - o conceito de comunidade urbana é proposto como um todo, como um organismo constituído de partes que possuem relações $\mathrm{e}$ funções entre si.

Para Park (1948), a comunidade urbana seria composta por uma área de maior mobilidade, que corresponderia ao centro comercial, uma área ao redor deste centro (cortiços, áreas decadentes), área de apartamentos para a classe operária e uma área para as casas de classe média.

Park ressalta a importância que a comunidade assume ao apresentar um padrão que, invariavelmente, vem a ser uma constelação de áreas típicas que podem ser geograficamente localizadas e espacialmente definidas.

Ocorre, assim, uma distribuição espacial dos seres e atividades humanas, que são resultantes das forças competidoras.

Nesse processo, ocorre a mobilidade, o movimento da população. A mobilidade seria representada pela mudança de residência, de emprego, pela mudança da posição ecolóqica. 
Assim, as mudanças sociais poderiam ser descritas em termos de movimentos, e o crescimento das cidades não envolveria somente o crescimento quantitativo, mas também as mudanças e movimentos que os indivíduos realizam para encontrar o seu lugar na vida urbana.

Fluidez - A fluidez é outro conceito proposto pelos ecólogos humanos e está vinculada ao desenvolvimento dos meios de transportes e comunicações; remete ao movimento do indivíduo, na comunidade urbana, sem a alteração da sua posição ecológica.

Além destes conceitos, que não são únicos, os ecólogos humanos identificaram, no estudo das cidades, formas espaciais de agrupamentos que interferem na organização da cidade e que receberam a denominação de processos ecológicos; entre eles, destacamos: concentração dispersão, centralização-descentralização, segregação, invasão e sucessão.

Concentração - Seria a reunião, em massa, de seres humanos e utilidades, em áreas onde a natureza ou o homem desenvolveram as condições favoráveis à satisfação das necessidades de sustento, sendo, a mesma, medida, através da densidade.

A concentração, em uma região, implica em uma dispersão em outra, pois tudo o que facilita a mobilidade/ locomoção das pessoas implica em dispersão.

Centralização - Seria a integração dos seres humanos e facilidades, ao redor de pontos focais, onde ocorre, com mais frequência, a integração social, econômica e cultural. Na área central, se concentrariam as principais atividades econômicas, sociais e culturais da cidade.

Com a tendência à multiplicação dos centros nas cidades e da mobilidade da população para a periferia, teríamos $\circ$ processo de descentralização.

Segregação - Para os representantes da Escola de Chicago, a segregação refere-se ao processo de seleção que ocorre em uma comunidade urbana, resultante, basijamente, mas não exclusivamente, da competição econômica que determina a distribuição ecológica da população na cidade. Seria uma concentração de grupos populacionais, dentro de um dado território, sendo a expressão espacial a "área natural." 
Invasão - Seria a penetração de uma área segregada por um grupo de população diferente do que a ocupa. É um processo de substituição de um grupo por outro, muitas vezes ligado a mudanças nos usos do solo.

Sucessão - É o resultado final de um ciclo de invasão e corresponde a uma mudança de utilização do solo ou do grupo populacional.

Para os ecólogos humanos, a estrutura da cidade depende da ação dos processos ecológicos, pois os mesmos criam a configuração espacial da cidade.

O crescimento da cidade ocorreria do centro para a periferia e seria representado por zonas concêntricas, onde, no processo de expansão, cada zona invade a imediatamente contígua, criando o ciclo invasão-sucessão.

Dessa forma, a abordagem proposta pela Escola de Chicago seria a de "estudar as comunidades urbanas procurando verificar as forças que atuam dentro dos limites dessas comunidades" [Park (1947)].

Park também considera a cidade como sendo o produto da natureza humana, onde a mesma estaria envolvida pelos processos ecológicos, porém a considera, também, como sendo o "habitat natural do homem civilizado."

Park estabeleceu um programa de investigação para o estudo da vida urbana, compreeendendo a sua organização física, suas ocupações, sua cultura, e entre os pontos que orientaram essa investigaçaão pode-se destacar:

- a planta da cidade e a organização local;

- a organização industrial e a ordem moral;

- as relações secundárias e o controle social; e

- o temperamento e o meio urbano.

Já para Burgess (1974), o crescimento das cidades deveria ser feito levando-se em consideração a expansão como processo.

Para tanto, propõe que o processo típico de expansão da cidade poderia ser ilustrado por uma série de círculos concênctricos que designariam tanto as zonas sucessivas de expansão urbana como os tipos de áreas diferenciadas no processo de expansão.

Essa diferenciação estaria vinculada ao uso do solo e seriam identificadas, basicamente, cinco áreas no processo de expansão urbana. 
A proposta de crescimento da cidade, apresentada por Burgess, tem como área empírica a cidade de Chicago. $\mathrm{O}$ autor considera, o crescimento, como sendo um processo cuja tendência é o da expansão, do centro comercial, para a periferia.

O modelo proposto por Burgess apresenta cinco áreas onde: a área I seria o círculo central do mesmo e representaria a área central da cidade, área que integra a vida e a função da cidade e que apresenta relações de centralidade com todos os outros processos da vida urbana; a área II representaria a área de transição e seria caracterizada pelo valor elevado dos preços da terra, apresentando edifícios velhos e áreas decadentes, com prostituição e delinqüência; a área III abrigaria os pequenos apartamentos, com comércio pequeno, e seria a área de residência dos trabalhadores; a área IV conteria as residências dos membros da classe média; e a área $\mathrm{V}$ corresponderia à área de subúrbios.

Em seu modelo, Burgess procura mostrar a ação fundamental da expansão, cuja tendência, de cada setor interior, é estender-se para o exterior mediante os processos de invasão-sucesșão e concentração-desconcentração.

Podemos considerar, a partir da apresentação de alguns pontos propostos pela Escola de Chicago, que a mesma, em sua abordagem, procura tratar a sociedade em seus aspectos biológicos e simbólicos, isto é, aqueles que são resultantes da competição e da luta dos indivíduos, em qualquer ordem social, para sobreviverem e se perpetuarem.

Dessa forma, a Ecologia Humana, na sua proposta para a investigação da cidade, considera a mobilidade e a composição da população, a organização territorial e a divisão do trabalho (ocupações), a organização interna da cidade e os processos de mudanças no espaço urbano.

Na sua proposta de estudo da cidade, a Escola de Chicago buscou uma analogia biológica e na relação direta entre forma e função social, e através do conceito de competição, estudar o crescimento das cidades, sobretudo das metrópoles e da expansão urbana.

Os pesquiasadores da Escola de Chicago elegeram três asserções teóricas básicas para os estudos de Ecologia Humana [Gottdiener, (1993:35-36)]:

- a eficácia da analogia biológica; 
- o emprego de princípios do "darwinismo social" para explicar o comportamento humano; e

- a relação de valores simbólicos ao campo da psicologia social por serem secundários para o primado da competiçaõ econômica.

Gottdiener (1993:37) considera que a abordagem feita pelos ecólogos humanos se divide em duas fases:

"...a primeira constitui o modo como a Escola de Chicago anterior à Segunda Guerra Mundial aborda a teoria, a qual se concentrou em fatores behavioristas sociobiogênicos para explicar os padrões espaciais; a segunda, a perspectiva do pósguerra, localizada em vários lugares, que enfatiza uma visão sistêmica daqueles argumentos da sociedade ao meio ambiente, que são uma conseqüência de forças sociais básicas, como a competição econômica."

A contribuição mais importante da segunda fase da abordagem da Ecologia Humana foi feita por Hawley, com a publicação da obra "Human Ecology", onde buscou reter a analogia biológica em uma análise sócio-estrutural do crescimento e desenvolvimento da cidade. Procurou construir uma teoria de crescimento metropolitano que explicasse a forma urbana, onde considera importante o papel dos transportes e das comunicações para a explicação dessa forma.

A Escola de Chicago nos legou uma matriz teórico metodológica para a abordagem da cidade e do crescimento urbano, e que ficou conhecida como Ecologia Humana. No entanto, esta matriz apresenta limitações para explicar a cidade e o urbano. Estas limitações foram apontadas por vários autores, entre os quais destacamos Firey, Castells, Reismann e Gottdiener.

\section{2-LIMITES À ABORDAGEM DA ESCOLA DE CHICAGO}

Através de seus trabalhos, os pesquisadores da Escola de Chicago desenvolveram uma matriz teórico-metodológica que possibilitou a análise de uma série de fenômenos urbanıs.

Transpuseram os conceitos da Ecologia e os princípios do darwinismo para o estudo da sociedade. Utilizaram o modelo biológico, de cunho naturalista, para a análise dos fenômenos urbanos. 
Postularam que o meio social deveria ser estudado da mesma forma que o meio natural. Nesse contexto, a cidade era um meio natural, onde ocorreriam os processos ecológicos que poderiam ser estudados pelas mesmas técnicas e perspectivas utilizadas no estudo da natureza.

Assim sendo, a Escola de Chicago ficou conhecida, de modo geral, pela utilização dos métodos das ciências naturais. Suas características mais marcantes foram a analogia biológica e a análise empírica dos processos que ocorreriam nas áreas urbanas, sobretudo nas áreas metropolitanas, que apresentavam um grande crescimento no início do século, nos EUA, em decorrência da expansão do capitalismo industrial.

Os pesquisadores da Escola de Chicago criaram uma estrutura acadêmica que permitiu que suas idéias fossem debatidas e operacionalizadas com os seus discípulos.

Muitas críticas foram endereçadas às proposições teóricometodológicas da Escola de Chicago, sendo que, de forma geral, as críticas foram dirigidas contra as teorias gerais que sustentavam a Ecologia Humana.

Os maiores questionamentos à abordagem dos ecólogos humanos assentam-se no fato de transposição do método de análise das ciências naturais para as ciências sociais, a analogia biológica e dos mesmos terem deixado em segundo plano os fatores culturais.

modelo de crescimento da cidade, proposto por Burgess, também foi muito questionado. Argumenta-se que, em sua análise, Burgess baseia-se nos processos ecológicos sem levar em consideração outros fatores que participam da dinâmica urbana.

Entre os autores que questionaram as proposições da Escola de Chicago encontramos Firey (1945), que sugere a alteração das premissas básicas da teoria ecológica a respeito do espaço e das atividades locacionais, pois, para os ecólogos humanos, a relação entre espaço e atividades locacionais seria unicamente de caráter econômico, o que geraria um processo competitivo.

Firey denomina essa teoria de "ecologia econômica" e afirma que a mesma mostorou-se adequada para analisar a dinâmica espacial urbana apenas em um primeiro momento. Porém, à medida que esta teoria amadureceu e buscou ampliar o leque dos fenômenos a serem investigados, a partir da sua 
generalização teórica, foi necessário considerar outros aspectos que não os estritamente econômicos.

Firey desenvolve um trabalho sobre a cidade de Boston e indica a importância que assumem os fatores culturais para a análise do urbano, pois, para o autor, a cidade também é produto da cultura e não somente produto dos fatores ecológicos e biológicos.

Esse autor destaca o papel que os sentimentos dos membros da comunidade possuem em relação a determinadas áreas da cidade, fazendo com que as mudanças não se processem como propostas por Burgess em seu modelo. Certas áreas, que apresentam um valor cultural ou simbólico para as populações, resistem no processo de crescimento urbano.

O modelo de crescimento das cidades, em zonas concêntricas, proposto por Burgess, baseado nos processos ecológicos, transformou-se em referencia para os estudos sobre estrutura urbana e foi, por isso mesmo, muito contestado.

Burgess descreveu o crescimento urbano de Chicago no início do século que, devido ao rápido processo de industrialização e ao crescente fluxo migratório, passava por profundas transformações. Descreveu uma cidade que apresentava um crescimento rápido, em um momento histórico específico.

Por descrever uma determinada cidade, e em um determinado momento histórico, o modelo é específico para Chicago e não serviria para analisar outras cidades.

Castells considera o modelo simples, sendo que o mesmo "implicava num desenvolvimento em termos de seqüência temporal". O modelo não teria "nada de mágico" e corresponderia a uma descrição do desenvolvimento urbano correspondente a uma forma social determinada.

Assim sendo, as zonas concêntricas do modelo nada mais são do que - resultado de processos sucessivos de ocupações do solo, resultante da industrialização.

Burgess não levou em consideração os efeitos provocados pela zonificação, pela renovação urbana e pelos meios de transportes e comunicações, que influenciariam o crescimento urbano. 0 modelo proposto por Burgess "não passa de um processo social determinado" [Castells (s/d:32)]. 
O processo ecológico invasão-sucessão, contido no modelo, também é contestado por outros autores, além de Firey e Castells, que apontam algumas de suas limitações.

Molotch e Logan (1987) ponderam que a pressão, por crescimento e rendimentos, não consiste na única força do cenário urbano. Existem esforços individuais e coletivos que acentuam ou identificam os valores de uso do solo nas cidades. Os sentimentos e o caráter que assume a questão da vizinhança também influenciam na estruturação da cidade.

A cidade seria mais do que o processo de invasão-sucessão a partir da zona central. As transformações urbanas săo mais dinâmicas e, para os autores, o significado específico que os residentes dão ao lugar é moldado pela forma como elas utilizam os recursos materiais disponiveis no seu cotidiano.

$\mathrm{Na}$ constituição de uma vizinhança, os sentimentos e as necessidades concretas estão intimamente ligados, e a sua existência seria ameaçada através de uma pressão econômica insustentável sobre os moradores, o que poderia levar à desagregação. Porém, essa desagregação não ocorreria sem resistências.

Os ecólogos humanos descreveram a cidade como sendo um "mosaico de pequenos mundos" que se tocariam, mas não se interpenetrariam. Esta afirmação também é contestada, pois esses "mosaicos" são capazes de se interprenetrarem, e sua localização na cidade passa a ser decorrente também dos equipamentos urbanos e valor da terra.

Para Reissmann (1972), as críticas dirigidas à Ecologia Humana foram direcionadas contra a teoria que separou a sociedade da comunidade, da circunscrição das análises sociológicas em uma área delimitada, a cidade de Chicago.

Foram apontadas limitações, também, ao referencial teórico, baseado na analogia biológica e no emprego dos métodos das ciências naturais. A Ecologia Humana não colocou o investigador no contexto observado; ele encontrava-se fora do conıexto a ser estudado.

Concordamos com Gonçalves (1989), que considera que a Escola de Chicago apresentou também duas lacunas básicas em suas análises: a ausência do Estado e os processos sociais gerais. 
No entanto, apesar da sua fragilidade teórica, das limitações expostas, a Escola de Chicago formulou proposições importantes e relevantes para os estudos urbanos.

\section{A ABORDAGEM MARXISTA DO ESPAÇO URBANO}

A partir da década de 50 , ocorreu um rápido crescimento econômico, juntamente com a expansão do comércio internacional. As relações internacionais foram reestruturadas, os fluxos de capital, mão-de-obra e tecnologia foram estimulados, graças a eficientes e modernos sistemas de comunicação e circulação. Passamos a viver em um período que Milton Santos denomina de "técnico-científico" e que é representado pelas grandes indústrias e corporações, que provocaram transformações no território e no espaço.

A esta fase do capitalismo correspondem mudanças que provocaram alterações na organização do espaço. Entre estas mudanças, destacamos: a intensa urbanização, com a reestruturação das áreas metropolitanas em função de um grande processo migratório, que ocasionou um crescimento desordenado das cidades; o crescimento das atividades ligadas aos setores terciário e quaternário da economia; a mundialização do sistema financeiro; e a articúlação da economia em escala mundial.

Todas essas mudanças acarretaram alterações no meio urbano, transformações que o paradigma da Escola de Chicago não conseguia apreender e explicar.

Para explicar essas transformações, alguns pesquisadores, como Lefebvre, Harvey, Castells, entre outros, buscaram no marxismo os fundamentos básicos e incorporaram em suas pesquisas o materialismo histórico e dialético.

A introdução das teses marxistas nos meios acadêmicos ocorreu no final dos anos 60 e início dos anos 70 . Desenvolveu-se, assim, outra matriz teórico-metodológica, um novo paradigma, que contou com a contribuição de várias disciplinas das ciências sociais, como a sociologia, a geografia, a economia e a ciência política.

O traço comum entre esses cientistas sociais se deu através de propostas similares e complementares. Assim, para a apreensão dos fenômenos 
a serem estudados, deve-se levar em consideração o modo de produção, o processo de acumulação do capital e os aspectos inerentes à força de trabalho. Destacaram o papel da produção, do Estado e da propriedade e infra-estrutura (o segundo circuito do capital) para a apreensão das relações sócio-espaciais.

A abordagem marxista representa uma alternativa para os estudos sobre o espaço urbano. Contribui, ao introduzir para a análise da cidade e do urbano, a teoria da acumulação (ou valor de uso e o valor de troca e o solo urbano), os agentes produtores do espaço urbano (os proprietários dos meios de produção e fundiários, os promotores imobiliários, o Estado e os grupos sociais excluídos) e o processo de segregação residencial.

Henry Lefebvre, filósofo francês, foi um dos pioneiros na análise do espaço e do urbano através da abordagem marxista. Considerou o espaço social da cidade (o espaço urbano) ao mesmo tempo reflexo e condição da sociedade, e apresentou em seu livro "Espacio y Política" (1976:23-42) quatro hipóteses sobre o espaço, onde contestou as três primeiras.

$\mathrm{Na}$ primeira hipótese, apresenta o espaço como absoluto, com existência autônoma. É um espaço que contém as coisas. Na segunda hipótese, considera o espaço como sendo um produto social. Na terceira hipótese, considera o espaço como local de reprodução da força de trabalho.

Estas três hipóteses são rejeitadas, pois a primeira refere-se ao espaço da matemática; a segunda; ao estabelecer a relação direta entre sociedade e espaço, mostra-se mecanicista. Lefebvre considera a terceira hipótese incompleta, na medida em que não dá conta da totalidade.

Assim, propõe a quarta hipótese, onde afirma que o espaço é o locus da reproduçaõ social, envolvendo toda a sociedade em seus vários segmentos, incluindo a reprodução do capital.

O método dialético deve ser utilizado para a apreensão do espaço, pois permite uma definição geral das contradições que ocorrem no espaço, possibilitando o estudo do espaço-tempo diferentes, que apresentam redes e fluxos diferentes, que se sobrepõem.

A abordagem de Lefebvre centra-se na análise do modo de produção capitalista e no papel que o espaço representa na manutenção do mesmo. 
Considera que o capitalismo se manteve estendendo-se pela totalidade do espaço, e que atualmente se mantém através da produção do espaço. Passou-se da produção no espaço para a produção do espaço.

$\mathrm{Na}$ produção do espaço, destaca o papel que passou a representar o setor imobiliário, o "segundo circuito do capital". Esse "segundo circuito" passou a desempenhar um papel fundamental no processo de acumulaçăo do capital e, conseqüentemente, da produção do espaço urbano, onde o valor de uso do espaço vai ser estabelecido no seu consumo.

Lefebvre (1976:101) identifica, assim, os agentes da produção imobiliária que interferem na produção do espaço urbano: os proprietários, os promotores, o poder público (Estado), o sistema financeiro, as coletividades locais, os usuários e os arquitetos.

Nesse contexto, o capitalismo sobreviveu através da ocupação do espaço e, atualmente, sobrevive através da produção do espaço. O sistema atenua as suas contradições internas e assegura a sua existência, sendo que, atualmente, é o espaço urbanizado que se constitui na base material de reprodução ampliada das estruturas sociais do capitalismo.

A contribuição de Henry Lefebvre para as ciências sociais é vasta, além de ele ser um dos pioneiros em realizar a abordagem marxista nos meios acadêmicos. Gottdiener (1993:158) considera que as contribuições de Lefebvre fornecem "o alicerce teórico para o desenvolvimento de uma nova abordagem."

Entre as suas idéias que orientam os estudos urbanos está o restabelecimento em outros termos da questão do espaço, assinala, ainda que a sociedade em que vivemos é urbana e ressalta a importância do setor imobiliário na produção do espaço urbano, além de realizar a conexão entre segregação e classes sociais.

Consideramos Lefebvre um referencial significativo na construção da abordagem marxista. Ao lançar os fundamentos da abordagem marxista aos estudos urbanos, influenciou pesquisadores que realizaram várias pesquisas que contribuíram para uma aríślise mais crítica das relações sócio-espaciais.

Entre os temas pesquisados, destacamos os que se referem ao valor de uso e troca, o solo urbano, os agentes produtores do espaço urbano e a segregação residencial. 


\section{1- O SOLO URBANO E A TEORIA DO VALOR DE USO E VALOR DE TROCA}

Os autores que empregam a teoria do valor de uso e do valor de troca procuram entender o papel que desempenha o espaço urbano do capitalismo. Analisam o processo de acumulação do capital e a reproduçaõ de mais-valia para explicar como "os processos de desenvolvimento da cidade ou urbanização são a manifestação espacial do processo de acumulação" [Gottdiener (1993:93)].

Direcionam suas pesquisas para a apreensão do espaço construído, o setor imobiliário, ou seja, o circuito secundário do capitalismo, como proposto por Lefebvre. Assim, é importante, no entendimento da teoria do valor de uso e do valor de troca do solo urbano, o papel que desempenha a renda e a influência da mesma na produção do espaço urbano.

Lefebvre (1976) nos chama a atenção para a importância que o setor imobiliário assume no capitalismo. O setor imobiliário passa a fazer parte de um primeiro plano, ainda que de forma desigual e segundo a conjuntura de cada país.

A importância desse setor está vinculada à conversão em bens móveis do espaço, e esse processo apresenta algumas exigências, como: o solo deve ser retirado da influência dos proprietários tradicionais e receber um valor de troca. O lugar passa a ser visto como uma mercadoria, onde a propriedade privada e a especulação são fatores necessários.

Nesse processo, o comprador adquire o valor de utilização, o valor de troca e o valor de uso que se encontram em uma relação dialética, onde o que se paga se refere às rendas, que dependem do solo e da propriedade do solo.

A renda da terra urbana assume um aspecto importante para a análise, pois é um dos elementos que permitem a apreensão do urbano. O preço da terra e a sua renda apresentam ur forte efeito sobre a forma urbana, como a distribuição sócio-econômica da popútáăcicie na cidade.

Assim, a análise sobre o ambiente construído nas cidades vai se pautar, basicamente, nas proposições de Marx e Lefebvre.

Parte-se da concepçaõ de que, na sociedade capitalista, toda mercadoria apresenta um duplo aspecto: valor de uso e valor de troca; e, para Marx, toda mercadoria apresenta valor de troca para seu possuidor e deve representar valor de uso para o seu aquisidor. 
Assim, o método marxista, ao colocar o valor de uso e o valor de troca em relação dialética entre si, contribui para os estudos de uso do solo urbano.

Harvey, geógrafo inglês, foi um dos pesquisadores que desenvolveram seus trabalhos na perspectiva do ambiente construído nas cidades segundo a abordagem marxista.

Considera, o espaço, como local de reprodução das relações de produção e fundamenta-se na teoria do valor para explicar o ambiente construído nas cidades.

Nesse contexto, o solo e suas benfeitorias se apresentam, na economia capitalista contemporânea, como mercadorias, mas que se diferenciam das demais, por não poderem se deslocar livremente; por possuírem localização fixa e conferirem privilégios de monopólios para quem tem direito a definir seu uso; por serem indispensáveis; por trocarem de proprietário com pouca freqüência; e por apresentarem usos diferenciados.

Apresentam um longo período na sua utilização e, em decorrência, seus custos de obtenção são altos. Os valores de uso refletem os diferentes elementos da sua composição.

Harvey (1980) identifica os grupos que operam no mercado de moradia nas cidades. Para esses grupos, o valor de uso e o valor de troca variam de acordo com o interesse particular de cada um. Para os usuários, a moradia apresenta valor de uso que é determinado pela situação pessoal e de localização. Para os corretores imobiliários, a moradia significa valor de troca. Os proprietários, na maioria das vezes, transacionam para a obtenção do valor de troca. Os incorporadores e os construtores possuem interesse nos valores de uso para terceiros, com o objetivo de mobilizarem para si os valores de troca. 0 sistema financeiro desempenha um papel importante e se interessa pelo valor de troca, na medida em que possibilita a terceiros, via financiamentos, a aquisição de valores de uso. O Estado interfere de forma direta, através da produção de valores de uso, ou de forma indireta, através de apoio ou financiamento aos promotores imobiliários na obtenção de valores de troca. O papel do Estado é significativo no setor imobiliário. Para esses grupos, o valor de uso e o valor de troca variam de acordo com o interesse particular de cada um. 
O solo e a moradia são mercadorias que dependem da açăo conjunta do valor de uso e do valor de troca, e, a "teoria do uso do solo aparece, então, com o problema seqüencial de ocupação do espaço, com a possibilidade de espaço adicional na periferia (...), onde os que têm dinheiro têm mais chances, enquanto, os mais pobres pegam o que sobrou" [Harvey (1980:144)].

A diversidade de grupos que atuam na questão do uso do solo, mais a qualidade monopolista que apresenta o espaço absoluto, através da propriedade privada, remetem à necessidade de investigar o papel da renda no sistema urbano.

A evolução dos padrões de uso do solo urbano deve ser entendida em termos de processo geral, e a condição da forma urbana faz parte desse processo geral; a renda contribui para o seu entendimento, como medida de interpretação dos valores de uso e valores de troca.

Originalmente, a noção de renda foi aplicada ao solo agrícola, sendo que o aspecto comum com o solo urbano é a propriedade privada do solo.

$A$ renda do solo urbano funcionava como um artifício racional que selecionaria os usos dos solos em localizações, e se apresentaria sob três formas: renda absoluta, renda monopólio e renda diferencial.

A renda absoluta é derivada da propriedade privada, de onde se extrai um rendimento. A renda monopólio é aquela que, além de extrair o excedente do fato de a propriedade ser privada, extrai algo mais em função do atributo do monopólio gerado pela localização ou status social e pela absorção desses valores pelo mercado. A renda diferencial provém de várias combinações associadas ao uso do solo, onde a localização e o custo dos transportes são fatores importantes.

A renda constitui-se numa parte do valor de troca de que se apropria o proprietário e dono do solo. A renda, em qualquer de suas formas, desempenha um papel importante, uma vez que proporciona uma direção para a interpretação dos valores de uso e trocis do solo urbano.

Para Harvey (1980:164), "a renda existe somente em sentido contingente, depende do modo de produção e de certas instituições relativas ao domínio da propriedade". Sendo assim, não pode haver algo como uma teoria do uso do solo 
urbano "geral", e todas as teorias de uso de solo devem ser vistas como passíveis de contribuição aos estudos urbanos.

Assim, os valores de uso e de troca devem ser vistos de uma forma relacional e dialética, bem como a atuação dos agentes no processo de produção do espaço urbano, onde o que representa o valor de uso e o valor de troca para os mesmos está na dependência das relações sociais de cada um dos agentes envolvidos no processo, ocorrendo, assim, uma diferenciação residencial no espaço urbano.

Isso ocorre devido à lei do valor no espaço ser estruturada e manipulada pela classe dominante, onde o preço da terra e a renda apresentam um forte efeito sobre a forma urbana.

Esta teoria procura analisar o setor imobiliário, o ambiente construído nas cidades, através da relação entre o valor de uso e de troca do solo urbano, suas construções e da obtenção de uma renda nesse processo.

Essa análise do ambiente construído do setor imobiliário é importante porque introduz uma abordagem espacial do processo de acumulação do capital.

\section{2 - OS AGENTES MODELADORES DO ESPAÇO URBANO}

$\mathrm{Na}$ abordagem marxista do espaço, são identificados e analisados os agentes sociais concretos que modelam o espaço urbano, agentes que apresentam estratégias e são integrantes dos conflitos que ocorrem na cidade.

Corrêa (1989:7-10) pondera que o espaço urbano no capitalismo seria, em um primeiro momento, um conjunto de diferentes usos da terra justapostos entre si. Esses diferentes usos resultam em áreas diferenciadas, como - centro da cidade, áreas industriais, áreas residenciais, áreas de lazer e de expansão. Assim sendo, o espaço urbano apresenta várias características, é articulado e fragmentado, é reflexo e condição social, é campo simbólico e de lutas, e permite diferentes formas de análise para a sua apreensão.Lefebvre (1976) é dos primeiros cientistas sociais a refletir sobre o urbano na abordagem marxista. Segundo o autor, vivemos em uma sociedade urbana, e ele analisa as transformações que ocorrem na sociedade e no espaço, inseridas no modo capitalista de produção. 
Para Lefebvre, o capitalismo tem se mantido através da conquiista, da integração e da produção do espaço; a cidade apresenta-se nesse contexto como fragmentada e converte-se, cada vez mais, em centro de poder e de fonte de benefícios. A cidade passa a fazer parte das grandes empresas, pois proporciona inúmeros serviços, e passa a ocorrer um verdadeiro consumo produtivo do espaço, além de utilizar uma imensa força de trabalho mal remunerada para a sua conservação. Trabalhadores são alijados do centro urbano através da segregação econômica, social e cultural, e esse processo ocorre também devido à propriedade privada do solo.

No processo de expansão de capitalismo que, para Lefebvre, mantém-se estendendo-se pela totalidade do espaço, o setor imobiliário encerra relações sócio-espaciais e assume importância considerável. O setor imobiliário converteu o espaço, o solo, e bens móveis, através de construções e especulações, pois, para o autor, esse setor reverte-se de grande importância na expansão do sistema capitalista, variando de acordo com a conjuntura dos países.

Nesse processo de produção do espaço, Lefebvre identifica os agentes da produção imobiliária, os proprietários, os promotores imobiliários, o sistema financeiro, o Estado, os usuários, as coletividades locais e os arquitetos.

A classe dominante controla esse mercado, sobretudo através da propriedade do solo, e, através de um capitalismo de organizações, domina e mantém um mercado frágil, porém sempre em expansão. Essa classe utiliza o espaço para dispersar a classe trabalhadora, organizar os fluxos, subordinar o espaço ao poder e controlar o espaço.

Assim, a questão do setor imobiliário, da habitação, converte-se em uma parte da questão urbana e faz-se necessária uma reflexão da ação desses agentes para a compreensão do espaço urbano.

Lefebvre vai além da identificação e análise do processo de produção do espaço urbano; para ele, deve-se lutar pelo direito à qualidade de vida, pelo direito à cidade, através da apropriação coletiva do espaço.

David Harvey vai analisar o ambiente construido nas cidades através da abordagem marxista, onde considera importante a teoria da acumulação do 
capital e a luta de classes, e vai ressaltar os mecanismos que atuam na construção do espaço urbano.

Analisa a teoria do valor de uso e do valor de troca, o uso do solo urbano e o papel do espaço urbano no desenvolvimento do capitalismo. Identifica os grupos que atuam no mercado de moradia: os usuários, os proprietários, os corretores, os incorporadores e os construtores, o sistema, financeiro e o Estado. Para cada um desses grupos, o valor de troca varia de acordo com o interesse particular de cada grupo.

Durand-Lasserve, em seus trabalhos, também apresenta os agentes que operam no processo de produção fundiária e imobiliária, que produzem espaço urbano. Assim, para este autor, na produção do espaço urbano teríamos a ação dos seguintes agentes: proprietários fundiários e imobiliários urbanos; produtores de materiais de construção; promotores imobiliários e incorporadores; os detentores do capital; os compradores de terrenos e habitações; os ocupantes de áreas urbanas; o poder público e as instituições transnacionais.

Para Corrêa (1989), o espaço urbano capitalista é um produto social produzido por agentes que produzem e consomem espaço, sendo ação das mais complexas, que resulta na constante reorganização espacial da cidade.

Para a compreensão desse espaço urbano complexo, que é constantemente reorganizado pelos agentes que o produzem, Corrêa (1989) identifica cinco grupos de agentes sociais: os proprietários dos meios de produção, sobretudo os grandes industriais; os proprietários fundiários; os promotores imobiliários; o Estado e os grupos sociais excluídos.

Os agentes apontados pelos autores mencionados, em sua maioria, são coincidentes, e não poderia ser diferente, uma vez que esses agentes estão inseridos no processo de acumulação de capital, pois, como indica Lefebvre (1976), a classe dominante serve-se do espaço como um instrumento para viabilizar os seus propósitos. Isso ocorre, em grande parte, devido à propriedade privada, a posse e o controle da terra urbana.

Faremos, ass:m, uma breve caracterização dos agentes produtores do espaço urbano a partir da proposta de Corrêa (1989): os proprietários dos meios de produção, os proprietários fundiários, os promotores imobiliários, o Estado e os grupos sociais excluídos. 


\subsection{1 - Os proprietários dos meios de produção}

Influenciam de forma direta na definição do espaço social da cidade e săo grandes consumidores do espaço, em função de necessitarem de grandes parcelas de terra para a instalação das fábricas e dos depósitos de mercadorias. Normalmente, procuram fixar suas empresas próximas à rede de infra-estrutura, como portos, rodovias, ferrovias, sistema de telecomunicações. "A terra urbana tem, assim, em princípio, um duplo papel: o de suporte físico e o de expressar diferencialmente requisitos locacionais específicos às atividades" "[Corrêa $(1989: 13)]$

Dessa forma, as relações que se estabelecem entre os proprietários dos meios de produção (industriais) e o espaço não dizem respeito somente ao tamanho e à relação custo-benefício, mas também aos requisitos locacionais. $A$ esta classe não é interessante a especulação fundiária, uma vez que o aumento do solo urbano implica em um aumento de custos. Assim, a especulação fundiária contraria os interesses da burguesia industrial e interessa, de maneira direta aos proprietários fundiários, o que gera conflito entre esses dois agentes que modelam o espaço urbano.

Os proprietários dos meios de produção criam áreas industriais em setores da cidade distintos das áreas comerciais e residenciais das elites, e pressionam o Estado no sentido de dotar de infra-estrutura essas áreas, além de facilitar a construção de habitações populares para a força de trabalho. Esse processo se dá, fundamentalmente, nos grandes centros urbanos.

Os proprietários podem induzir a população de baixa renda a se localizar nas áreas menos nobres do espaço urbano, ao fixar suas instalações em áreas próximas a elas.

\subsection{2 - Os proprietários fundiários}

Os proprietários fundiários, como detentores de porções do solo urbano, possuem o interesse na obtenção da maior renda possivel e na maior rentabilidade de seu uso.

A utilização comercial e residencial de status são mais rentáveis do que os outros tipos de uso. Os proprietários fundiários se empenham para que 
haja uma utilização intensiva do solo urbano, através da multiplicação do uso ou da verticalizaçăo.

Induzem a expansão do espaço urbano para realizarem a conversão das terras rurais em urbanas, que apresentam uma valorização maior. Estão interessados no valor de troca do solo urbano e normalmente direcionam seus interesses para a periferia das cidades, em um processo de valorização fundiária.

Sendo a terra urbana um produto social, que pressupõe um processo de transformação, através da implantação de uma infra-estrutura, como instalação de redes de água, esgotos, energia elétrica, de coleta de lixo e pavimentação, os proprietárioa fundiários pressionam o poder público para que estabeleça a mesma nas áreas de expansão, para uma maior valorização de suas propriedades.

Assim, é necessário conhecer a influência dos proprietários fundiários no contexto local e o peso que possuem para pressionar na definição do zoneamento e na normatização do uso do solo.

Para Corrêa, existem dois tipos fundamentais de proprietários fundiários atuando na periferia: os que estão tradicionalmente vinculados à oligarquia rural e urbanizam suas terras em função da proximidade do espaço urbano, e os proprietários que estão ligados às atividades urbanas e que investem na periferia urbana.

No entanto, o processo de passagem da terra agrícola para urbana é complexo, e "envolve diferenciais de demanda de terras e habitações, da direção em que esta transformação se verifica e das formas que ela assume; esses diferenciais atuam mais ou menos de modo combinado" [Corrêa (1989:17)].

Os proprietários fundiários desempenham um papel importante no processo de expansão do espaço urbano. No entanto, encontram-se atrelados às condições que interferem na demanda de terras e habitações, que se refletem no crescimento populacional e espacial desigual entre as cidades.

\subsection{3 - Os promotores imobiliários}

Representam um conjunto complexo que realiza diferentes funções no mercado imobiliário. 
Realizam as atividades de incorporação, financiamento, estudos técnicos, construção e comercialização. Essas atividades refletem a divisão social do trabalho no processo de promoção de imóveis. Promotor imobiliário é todo segmento desse mercado que cumpre uma ou mais dessas funções, e que apresenta as seguintes características em cada atividade:

Incorporação - A lei 4.591 considera como incorporador "a pessoa física ou jurídica, comerciante ou não, que, mesmo não efetuando a construção, negocia ou efetua a venda das frações ideais do terreno em imóveis que serão construídos ou que estão em construção, sob o regime de condomínio, ou que aceita simplesmente a proposição de efetuar tais transações, que coordena $\mathrm{e}$ efetua a incorporação, e ainda é responsável pela conclusão e entrega do imóvel num determinado prazo, a um certo preço e em condiçōes determinadas."

O incorporador constitui-se em uma peça fundamental no processo de produção imobiliária. Ele define todo o processo de produção do imóvel, é responsável pela obra e pela transformação do capital (dinheiro) em mercadoria (imóvel), e, em seguida, pelo processo de transformação da mercadoria no dinheiro ampliado (D-M-D').

É o incorporador quem obtém e faz a gestão do dinheiro, e realiza a comercialização. É o responsável nas questões legais do processo e quem define a dimensão e a qualidade do imóvel.

O incorporador mediatiza as relações com o proprietário fundiário e define a localização, a dimensão e a qualidade do imóvel.

Em função de sua gama de atuação, conhece muito bem o espaço urbano e especialmente o potencial de lotes urbanos. Escolhe os participantes para as funções que considera necessárias, definindo, assim, quem vai construir, financiar, comercializar e divulgar o imóvel.

Financiamento - Está atrelado ao incorporador que reúne as condições para a provisão de recursos para a viabilização do imóvel. Realiza gestões para o financiamento entre os interessados no imóvel ou junto a instituições financeiras plíslicas ou privadas. Normalmente, o financiamento é de origem externa.

Estudo Técnico - Feito por empresas que realizam um estudo de viabilidade técnica e econômica do imóvel. Este estudo permite ao incorporador 
definir as características do imóvel. Essas empresas podem ou năo estar vinculadas ao incorporador.

Construção - A construção do imóvel é realizada por empresa especializada e com tradição no ramo, designada pelo incorporador. A força de trabalho está vinculada diretamente à empresa construtora.

Comercialização - A estratégia de comercialização do(s) imóvel(s) e a conseqüente transformação do capital-mercadoria em capital-dinheiro acrescido dos lucros será realizada por uma empresa especializada que pode ou não estar vinculada à incorporadora.

Essas funções podem apresentar arranjos diferenciados de acordo com os interesses envolvidos na realização do imóvel. Existem promotores que executam apenas uma das funções (comercialização ou construção) ou que executam duas ou mais funções (incorporação, construção e comercialização).

Os promotores imobiliários, normalmente, estão envolvidos na produção para a chamada demanda solvável para a classe média e a de alto status. A produção de imóveis para as camadas populares, via de regra, conta com a ajuda do Estado.

Os promotores imobiliários, ao atuarem de forma desigual na construção de imóveis na cidade e estarem interessados no valor de troca dos imóveis, ratificam o processo de segregação, a imposta ou a auto-segregação no espaço urbano.

\subsection{4 - O Estado}

O Estado é o agente que atua na produção do espaço urbano mais complexo, por apresentar várias características em relação a essa produção. Para a abordagem marxista do espaço urbano, o Estado é um elemento fundamental na compreensăo da questão urbana. O Estado age no sentido de criar as "condições gerais da produçăo capitalista" através da intervenção via planejamento urbano.

O Estado é multifuncional, desempenha vários papéis e sua ação ocorre na medida da intensidade e da natureza dos conflitos. 
Os demais agentes produtores do espaço urbano possuem estratégias com objetivos determinados, mas o papel do Estado pode ser mutável. Ele pode ser proprietário fundiário, dos meios de produção, promotor imobiliário e agente financeiro, além de ser um aparelho ideológico e normatizador do processo produtivo.

Entre os instrumentos que utiliza para a normatização do espaço urbano podemos citar: regulamentação do uso do solo, taxação de impostos, localização dos equipamentos urbanos e produção do solo urbano.

A ação do Estado se processa em três níveis político-administrativos e espaciais: federal, estadual e municipal, e a esfera de atuação de cada um está expresso na constituição de cada país.

Para Corrêa (1989:26), o Estado visa "criar condições de realização e reprodução da sociedade capitalista, isto é, condições que viabilizem o processo de acumulação e a reprodução das classes sociais e suas frações".

Estas são algumas das ações que o Estado realiza no espaço urbano, uma vez que se deve analisar com acuidade cada espaço em função das especificidades que apresenta.

\subsection{5 - Os grupos sociais excluídos}

$\mathrm{Na}$ sociedade capitalista, o acesso a bens e serviços não se dá de maneira igual para toda a população. Essa sociedade é composta por classes que se diferenciam, entre outras características, pelo acesso ao mercado formal de trabalho e aos bens e serviços produzidos socialmente.

A habitação é um desses bens cujo acesso é seletivo. Um enorme contingente populacional é excluído do mercado imobiliário.

A esse grupo social de baixa renda resta a alternativa de morar em cortiços, em conjuntos habitacionais construídos pelo Estado ou a autoconstrução.

Para o grupo que não consegue manter vínculos com um agente social, restam as favelas e a rua.

Esses grupos localizam-se, via de regra, nas áreas menos atraentes, naquele momento, para o capital e acabam produzindo o seu próprio espaço. 
Assim, são esses agentes que organizam e reorganizam a cidade, que produzem o espaço urbano, através das lutas que estabelecem entre eles e que vão configurando o espaço urbano.

\section{3 - A SEGREGAÇÃO RESIDENCIAL}

O conceito de segregação residencial foi apresentado pelos pesquisadores da Escola de Chicago, ao estudarem os tipos de população e sua distribuição no espaço.

Os autores marxistas, que abordam os processos da divisão social do espaço partem, basicamente, da hipótese de Lefebvre (1976), que afirma que o espaço é o locus da reprodução social, envolvendo toda a sociedade em seus diversos segmentos, incluindo a reprodução do próprio capital.

Estabelece-se, assim, a conexão entre a segregação e as classes sociais, onde a segregação residencial seria o reflexo espacial das classes sociais e das suas frações.

Harvey foi um dos cientistas sociais que analisaram a questão da segregação residencial ’a luz das teorias marxistas. Para Harvey (1985), a segregação residencial é produzida pela organização das forças externas aos indivíduos ou mesmo pelo desejo coletivo de grupos sociais particulares. Ele destaca o papel que as instituições financeiras e governamentais desempenham nesse processo, uma vez que interferem diretamente no mercado através da coordenação das "necessidades nacionais", que limitam a possibilidade de os indivíduos fazerem escolhas. Os mesmos devem adaptar as suas preferências à dinâmica da segregação residencial.

A segregação é um processo que caracteriza a cidade e é a espacialização das classes sociais. Baseado em Marx, Harvey nos indica que, no capitalismo, existem três forças que influenciam na comnosição das classes sociais: as forças primárıds, as forças residuais e as forças derivativas.

As forças primárias correspondem à divisão da sociedade em duas classes fundamentais: a que detém os meios de produção e a que detém a força de trabalho. 
As forças residuais são derivadas da instauração do capitalismo em uma sociedade pré-existente, onde ficam resíduos, como a classe de proprietários fundiários que transferem a renda para a cidade e a desestruturação no terceiro mundo do campesinato, com a conseqüente transferência dessa massa para a cidade, onde fica marginalizada.

As forças derivativas surgem da necessidade gerada para a preservação do processo de acumulação do capital, através da inovação tecnológica. Temos a fragmentação da classe capitalista e uma variação da composição da força de trabalho. A sociedade se torna mais fragmentada, com um mercado consumidor mais diversificado. As forças derivativas atenuam as forças primárias ao possibilitarem uma maior divisão social do trabalho.

Essas forças, ao estabelecerem classes antagônicas, viabilizam a mobilidade social em contextos diferenciados e apresentam uma espaçotemporalidade desigual.

A segregação residencial, para Harvey, deve ser interpretada como um meio de reprodução das relações sociais de produção.

A segregação no espaço e na cidade é realizada pela classe dominante como já indicou Lefebvre (1976), classe que controla o Estado, que intervém no mercado habitacional e normatiza o uso do solo nas cidades.

A segregação residencial está vinculada à capacidade que cada classe social apresenta para pagar pela habitação, ocasionando um acesso diferenciado aos bens e serviços da cidade.

Assim, a cidade, o espaço urbano, torna-se o lugar da reprodução das relações sociais de produção.

Além da segregação imposta, existe a auto-segregação, que ocorre, principalmente, através de condomínios fechados, nos grandes centros metropolitanos.

\section{CONSIDERAÇÕES FINAIS}

Desde o final do século passado, registra-se um crescimento intenso das cidades, principalmente em decorrência da industrialização. A preocupação 
com esse crescimento originou, no início do século, um grupo de pesquisadores que procurou estudar o crescimento e as condições de vida nas cidades.

Esse grupo, vinculado ao Departamento de Sociologia da Universidade de Chicago, desenvolveu uma série de estudos sobre a cidade e legou um corpo teórico sobre o urbano, que ficou conhecido como a Escola de Chicago.

Entre os cientistas que contribuíram para essa Escola, destacamos a figura de Park, que propôs uma agenda de pesquisa para o entendimento do fenômeno urbano e da organização espacial da cidade. Burgess propôs um modelo de análise de cidade, baseado em círculos concêntricos, originado nos processos de invasão-sucessão. Mckenzie teceu considerações sobre a abordagem ecológica nos estudos das comunidades urbanas.

Realizaram uma aproximação entre as ciências sociais e naturais, através da analogia biológica. Essa aproximação aconteceu em um momento histórico específico, em que ocorria a expansão da sociedade industrial e a consolidação do império colonialista associado à idéia de progresso. Vivia-se a época do liberalismo econômico, da competição econômica.

Neste cenário, desenvolveu-se o positivismo, que procurou dar um caráter de cientificidade aos conhecimentos e influenciou os rumos das atividades acadêmicas, uma vez que o marxismo estava circunscrito ao movimento operário.

A Escola de Chicago adotou a base interpretativa do positivismo - a Biologia em um primeiro momento e a Física posteriormente - como modelo científico. O social e o natural representavam versões do mesmo processo, que eram suscetiveis de apresentarem padrões repetitivos de ocorrências, o que representaria a possibilidade da utilização do mesmo método.

A Escola de Chicago converteu-se na mais acabada expressão do darwinismo social, comparando-se ao determinismo ambiental na Geografia.

Os pesquisadores da Escola de Chicago centraram suas análises nos fatores econômicos e não explicaram, de forma consistente, as desigualdades no uso do solo urbano.

Para os críticos da Escola de Chicago, o crescimento urbano é mais dinâmico do que o processo invasão-sucessão sustentado na competição 
econômica. As transformações urbanas são dinâmicas e decorrentes, também, dos processos sócio-culturais.

Apesar do possível questionamento das suas formulações teóricas, a Escola de Chicago nos legou proposições importantes para os estudos urbanos.

Deixou de tratar dos aspectos fundamentais para a compreensão da cidade, como o papel do Estado e dos processos sociais, temas que serão investigados pelos marxistas.

O desenvolvimento das forças produtivas, após a Segunda Guerra Mundial, resultou na evolução do modo de produção capitalista, onde se materializaram novas condições para a realização dos diferentes momentos da produção, circulação e consumo. A reprodução ampliada do capital passou a ocorrer em outras bases.

Essas transformações ocorreram, também, no espaço e, mais especificamente, nas cidades. As áreas metropolitanas passaram por grandes transformações, devido ao intenso crescimento demográfico e do setor de comércio e serviços, o que suscitou uma gama de novas questões.

A Ecologia Humana tradicional encontrou dificuldades para explicar essas transformações. Face a essa nova realidade, reviu seus procedimentos de análise. Porém, a Néo-Ecologia continuou a centrar as suas análises "na interdependência funcional, na diferenciação espacial e nas relações biogênicas" [Gottdiener (1993:47)], e continuou a fazer uma análise abstrata dos conhecimentos sociais.

Uma análise materialista e dialética dos fenômenos sociais que ocorriam nas cidades teve início nos meios acadêmicos, na década de 60 , com a introdução dos conceitos marxistas nas universidades.

A contribuição pioneira nessa direção foi realizada por Henry Lefebvre, que considerou o espaço o locus da reprodução social que envolve toda a sociedade em todos os seus segmentos. Nessa perspectiva, o espaço social da cidade (o espaço urbano) é, ao mesmo tempo, reflexo e condição da sociedade.

O materialıımo histórico e dialético orienta os mais diversos representantes das ciências sociais, que são agrupados na Escola Marxista.

Destacamos as contribuições de Lefebvre, Harvey, Castells, entre outros. 
A Escola Marxista, em suas análises, procura especificar as sociedades conforme o modo de produção em que estão inseridas. Assim, os conceitos de classe social, relações de propriedade, Estado e modo de regulação da produção e reprodução são importantes.

Esses autores procuram estudar o papel que o espaço urbano desempenha no processo de desenvolvimento do capitalismo. Consideram importante a teoria do valor de uso e do valor de troca para estudar a utilizaçăo do solo urbano, além de identificarem os agentes que atuam na produção do espaço urbano.

Destacamos, também, a análise do setor imobiliário, o segundo circuito do capital, a apreensão da forma de acesso à moradia e a segregação residencial.

Caracterizamos duas das escolas que contribuem para os estudos da realidade urbana: a Escola de Chicago e a Escola Marxista, Escolas que são antagônicas em seus fundamentos, mas que apresentam, em seu conjunto, importantes formulações teóricas.

A Escola de Chicago fundamenta-se no positivismo e no darwinismo social, com uma visão abstrata dos acontecimentos sociais. A Escola Marxista é fundamentada no materialismo histórico e dialético, e se preocupa com as relações sócio-espaciais que se efetuam na realidade.

As duas escolas oferecem importantes contribuições para a análise do espaço urbano. Ambas são passiveis de críticas e não são infaliveis na explicação dos fenômenos urbanos. A opção do pesquisador por uma das escolas está relacionada com a visão de mundo, sua ideologia e prática de pesquisa.

\section{BIBLIOGRAFIA}

1.BOULMER, M. The Chicago School of Socioly. Chicago, The University of Chicago Press, 1984.

2.BURGESS, E. W. EI crescimento de la ciudad: introdución a un proyeto denvestigación. In THEODORSON, G. A. Estudios de Ecologia Humana 1. Barcelona, Labor, 1974. 
3.CAMPOS, P. A. A dinâmica imobiliária - Elementos para o entendimento da espacialidade urbana. Cadernos IPPUR/UFRJ,RJ. 3 (nr. especial): 47-70, 1989.

4.CARLOS, A. F, A. A cidade. SP, Contexto, 1992.

5.CASTELLS, M. Problemas de investigação em Sociologia urbana. SP. Martins Fontes, s/d.

6 A questão urbana. SP, Contexto, 1992.

7.CEGET. La Croissance Péripherique des villes du Tiers Monde. La rôle de la promotion foncière e imobilière.Talense, 1980.

8.CLARK, D. Introdução à Geografia Urbana. SP, Difel, 1985.

9.CORREAA, R. L. O espaço urbano: notas teórico-metodológicas.RJ, 1991 (mimeografado).

10 O espaço urbano. SP, Ática, 1989.

11.DAVIDOVICH, F. Focalizando conceituações no urbano. Revista Brasileira de Geografia. RJ, 45(1):137-148, 1983.

12.DELLE DONNE, M. Teorias sobre a cidade. Lisboa, Edições 70, 1979.

13.DURAND-LASSERVE, A. L'Exclusion des Pauvres dans les villes du Tiers Monde. Paris, L'Hormattan, 1986. FIREY, W. Sentimiento y simisolismo como variables ecológicas. In THEODORSON, G. A. Estudios de Ecologia Humana 1. Barcelona, Labor, 1974.

14.GONÇALVES, M. F. Processo de urbanização no Brasil: delimitação de um campo de pesquisa. Espaço \& Debates. SP, 28: 67-79.

15.GOTTDIENER, M. A produção social do espaço urbano. SP, Edusp, 1993.

16. GOTTDIENER, M. \& FEAGIN, J. R. Uma mudança de paradigma na sociologia urbana. Espaço \& Debates. SP, 28:44-58.

17. HARVEY, D. The urbanization of capital. Baltimore, The Jhon Hopkins University Press, 1985.

18. A justiça social e a cidade. Hucitec, SP, 1980.

19. HAWLEY, A. Ecologia Humana. Madrid, Tecnos, 1982.

20.HOLLINGSHEAD, A. B. Noções básicas de Ecologia Humana. In PEARSON, D. Estudos de Ecologia Humana.SP, Martins Fontes, 1948.

21.JARAMILLO, S. Produción de vivienda y capitalismo dependiente: El caso de Bogotá. Bogotá, CEDE, 1985. 
22.LEFEBVRE, H. Espaço y Política. El derecho a la ciudad, II. Barcelona, Península, 1976.

23. . La revolucion urbana. Madrid, Alianza Editorial, 1972.

24. . O pensamento marxista e a cidade. Lisboa, Ulissea, 1972.

25. O direito à cidade. SP, Ed. Documentos, 1969.

26.MCKENZIE, R. . Matéria - Objeto da Ecologia Humana. In PIERSON, D. Estudos de Ecologia Humana. SP, Martins Fontes, 1948.

27.MOLOTCH, H. e LOGAN, J.The urban Fortune. The Political Economy of Place. Barkeley, The University of California Press, 1987.

28.PARK, R. E. A cidade: sugestões para a investigação do comportamento humano no meio urbano. In VELHO, G. O fenômeno urbano. RJ, Zahar, 1973.

29. In PIERSON, D.

A comunidade urbana como configuração espacial e ordem moral.

30. Ecologia Humana. In PIERSON, D. Estudos de Ecologia Humana. SP, Martins Fontes, 1948.

31.REISSMAN, L. EI processo urbano. Barcelona, Gili S/A, 1972.

32.RIBEIRO, L. C. A. e LAGO, L. C. (org.). Acumulação urbana e a cidade. RJ, IPPUR/UFRJ, 1991.

33.SANTOS, M. A cidade e o urbano como espaço-tempo. In FERNANDES, A. e GOMES, M. A. (org.). Cidade e História. UFBA, 1992.

34.SEABRA, O. C. Encontro da Geografia com Henry Lefebvre: notas para uma avaliação crítica a partir da experiência de São Paulo. Anais do Terceiro ENGU. RJ, AGB, p.12-16, 1993.

35.TOPALOV, C. Les promoteurs immobiliers. Paris, La Haje, 1974.

36.VIERTLER, R. B. Ecologia Cultural. SP, Ática, 1988. (Série Princípios nr 148). 
